\title{
COMPOSITIONAL APPROACH OF 'SEBUAH PANTUN I' FOR SOLO PIANO BY TAZUL TAJUDDIN
}

\author{
Naili $R^{*}$ \\ Faculty of Music, Universiti Teknologi MARA, Malaysia
}

\begin{abstract}
The fusion between Asian culture and western music has widely influenced Tazul's compositional approaches. His influence from Malaysian poetry and gamelan music has been illustrated in his work Sebuah Pantun I. These influences have crafted a way of composing mediating Asian norms and western style which later he called 'gamelbati'. This article presents a detailed analysis of the first movement of Sebuah Pantun for solo piano employing the numbering systems of gamelan songs and the format of four-line 'pantun'. Sebuah Pantun for solo piano has four small subsections imitating the four-line 'pantun' which are two-line of 'pembayang' (shadow) and two-line meaning of the 'pantun'. The imitation of gamelan pelog scale and the format of four-line pantun incorporating Western instruments, notation and style has work perfectly in this composition work. Tazul's work also uses primarily five series of notes, but two extra notes were only used once throughout the piece. This suggests that the composer referred to the seven-tone of the pelog scale that was widely used in gamelan music. The composer uses serial composition as the main compositional approach in this work, where the notes are retrograded which then grouped to form several small sections imitating the four-line 'pantun'. Using the gamelan songs' numbering systems and four-line 'pantun' in his composition approach has explored the shape, space and musical aesthetic in an effective and imaginative way.
\end{abstract}

Keywords: music score analysis, pantun, gamelan, solo piano, Sebuah Pantun

\section{Introduction}

The compositional approaches of most Tazul Tajuddin's works have always been influenced by Malay and Islamic cultures. His unique style of composing is evident in his composition Sebuah Pantun I. The fusion of 'pantun' or Malaysian poetry, gamelan and music notation illustrates the combination of two different backgrounds into visually and audible elements through a new piece of music. Many western contemporary composers such as György Ligeti uses ostinato as a structural base in his Etude No 8, 'Fem'. Ostinato is usually a short repeated rhythm or phrase, widely used in South East Asian music elements such as gamelan (Henry, 2008). Creating and composing a new piece of music fused between two different dimensions of Asian culture - in this case, the Malaysian poetry of 'pantun' - and western art music is a typical trend for many Asian composers to produce original and interesting compositions. Hence, Tazul has proven this originality in his Sebuah Pantun mediating between South East Asia and the West, in the process.

Sebuah Pantun for solo piano or also known as Sebuah Pantun I is the first version of the seven-part composition works by Tazul Izan Tajuddin. As the title introduced, it is written for a single music 
instrument, which is the piano, however, the later versions of the work were expanded into different instrumentations such as for solo violin, solo flute, for voice and piano, guitar quartet, etc. Although there are many versions of instrumentation such for violin, for guitar etc, the composer still uses the same structural base and idea for all the compositional works. In this article, however, the music score analysis focuses particularly on the Sebuah Pantun for solo piano and will be discussing which compositional practices that have been employed by the composer during the process of the music composition. Through this analysis, one may have insight and a better understanding of how the composition has been pieced together, and how the composer transformed his imagination and ideas into a more concrete form of work, which is the musical score (Raja \& Yusri, 2020).

\section{Defining Music Score Analysis}

Based on the Cambridge Dictionary of Philosophy by Robert Audi, the definition of the word analysis is the process of breaking up a concept, proposition, linguistic complex, or fact into its simple or ultimate constituents. Therefore, analysis is the process of breaking the piece into smaller and simpler parts, so that its logical structure can be easily displayed and understood from the viewers' point of view (Blackburn, 1996). The purpose of music score analysis is to study how the composer engineered his imagination into something that can be read and played, which is the musical score. This basically can be achieved by studying the score carefully on how each component in the score contributes to shaping the composition based on the composer's intentions (Price, 2017). When analysing any music score, many elements can be investigated such as form, melody, harmony, rhythm, dynamic, music arrangement, instrumentation, etc. It is necessary to look at many elements of the score to determine whether if it's worth it in the context of the analysis. Music score analysis can be an effective way to gain an understanding of the composition process and how the elements work together (Hose, 2015). In his book of Music and Discourse: Toward Semiology of Music, JeanJacques Nattiez aesthetically mentioned that musical analysis is to show how a work of art functions.

Although the Sebuah Pantun for solo piano is only a one-page musical score, there are still obvious underlying layers that have been employed by the composer to achieve the sonority and characteristics of the composition. For instance, the numbering system that was adapted from the gamelan music fused with the four-line pantun creates the subtle yet profound melodic and harmonic structure, which is the foreground of the composition piece.

\section{Gamelan and Pantun}

In Sebuah Pantun I, the composer uses gamelan approach which later he calls 'gamelbati' as the mixture of the gamelan and using 'pantun' as the structural base. He then expands these ideas into different instrumentations yet still uses the same gamelan and pantun ideas.

Technically, in the composition work, there are numbering systems that imitate the gamelan songs and divide into four sections of verses one, two, three, and four. These verses indicate the four lines pantun which consist of 'pembayang' (shadow) and the meaning. In pantun, there are four lines in each stanza and usually, each line has four words. However, in traditional pantun, there are many written in two lines, six lines, or sometimes in sixteen lines in each stanza, but as for modern pantun, it is rare to find this kind of style anymore. Usually, the rhyme of four lines written in pantun is a-a-bb, a-b-a-b or a-a-a-a. In four lines pantun-, there are two different kinds of style in each stanza, that is, 
the first two lines act as a hint (shadow) of the meaning of the entire phrase. Then, the last two lines of the stanza act as a true meaning and usually are more straightforward and easier to understand. However, another style that we can find in each phrase is the first and the third line is a shadow, and the second and fourth line is the meaning. This approach was used in the piece Sebuah Pantun by Tazul Tajuddin.

Pelog is one of the scales in gamelan which consists of seven series of notes, this can be numbered as 1-2-3-4-5-6-7. Each number represents specific note, for example, 1(D)-2(Eb)-3(F)-4(G\#)-5(A)$6(\mathrm{Bb})-7(\mathrm{C})$. There are a series of notations in Sebuah Pantun that imitate pelog scales as in there are seven notes that have been applied to this composition.

\section{Materials and Data Collection}

Like other music score analysis, the primary source of the material is the musical score itself. A complete and thorough analysis will be done by deconstructing the composition piece in detail. This can be achieved by analysing each note in the score and then arranging them into a smaller group, in this case, it is arranged based on the gamelan numbering system and pelog scale. The result of the analysis will determine how the composer used the numbering system to construct the whole composition as the backbone of the Sebuah Pantun.

The other source of material that can help with the analysis is the recorded audio of the composition. This audio will be treated as supporting material to help the author in analysis process. However, it should not overcome the importance of the primary source, which is the music score analysis, as all information can already be found within the score itself including music notations, dynamic markings, tempo markings, playing techniques, rhythmic patterns, etc.

Another supporting material that can help to gain more understanding and insight into the compositional process is the performance notes that were written by the composer himself. These performance notes can be found within the score where the composer briefly discusses the main elements that comprised the whole idea of this work.

\section{Score Analysis of the Sebuah Pantun for Solo Piano}

In Sebuah Pantun for solo piano, Tazul writes in his performance notes as follows:

"A pantun is a traditional Malay verse form, commonly two or four lines long. My piece is derived from five series of notes and seven cycles of numbers. These weave around a hidden structure which is based around four small proportions, intentionally related to the four-line pantun. These elements are distributed throughout the piece. Strike the notes with conviction but in a calm and meditative state of mind, with a feeling of timelessness. For bars 2-22, two pedaling options are given"

There are five main notes in this piano piece, A-A\#-C\#-E-F. However, C and D appeared at the end of the composition. That means there are seven notes altogether. These main five series of notes, including the two extra notes, are influenced by pelog scale as well as in gamelan pelog which consist of seven series of notes. The piece starts with an introduction of the five series of notes and ends with the same figure. 


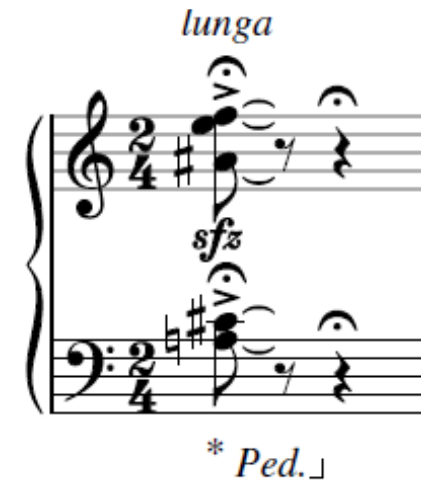

Figure 1: The first bar and introduction of Sebuah Pantun for solo piano.

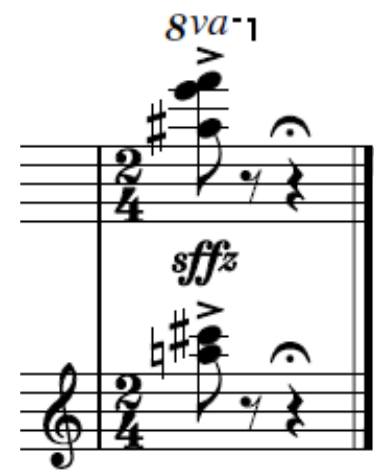

Figure 2: The final bar and ending of Sebuah Pantun for solo piano.

The notations of the first and last bar are the same but in different octaves and dynamic. The composer mentions that in his performance notes there are seven cycles of number in this piece. According to the pelog structure, the notation and numbering can be interpreted as $1=\mathrm{C} \#, 2=\mathrm{E}, 3=\mathrm{F}$, $5=\mathrm{A}$ and $6=\mathrm{A} \#$, then the introduction and the ending will be numbered as 5-1-6-2-3. 


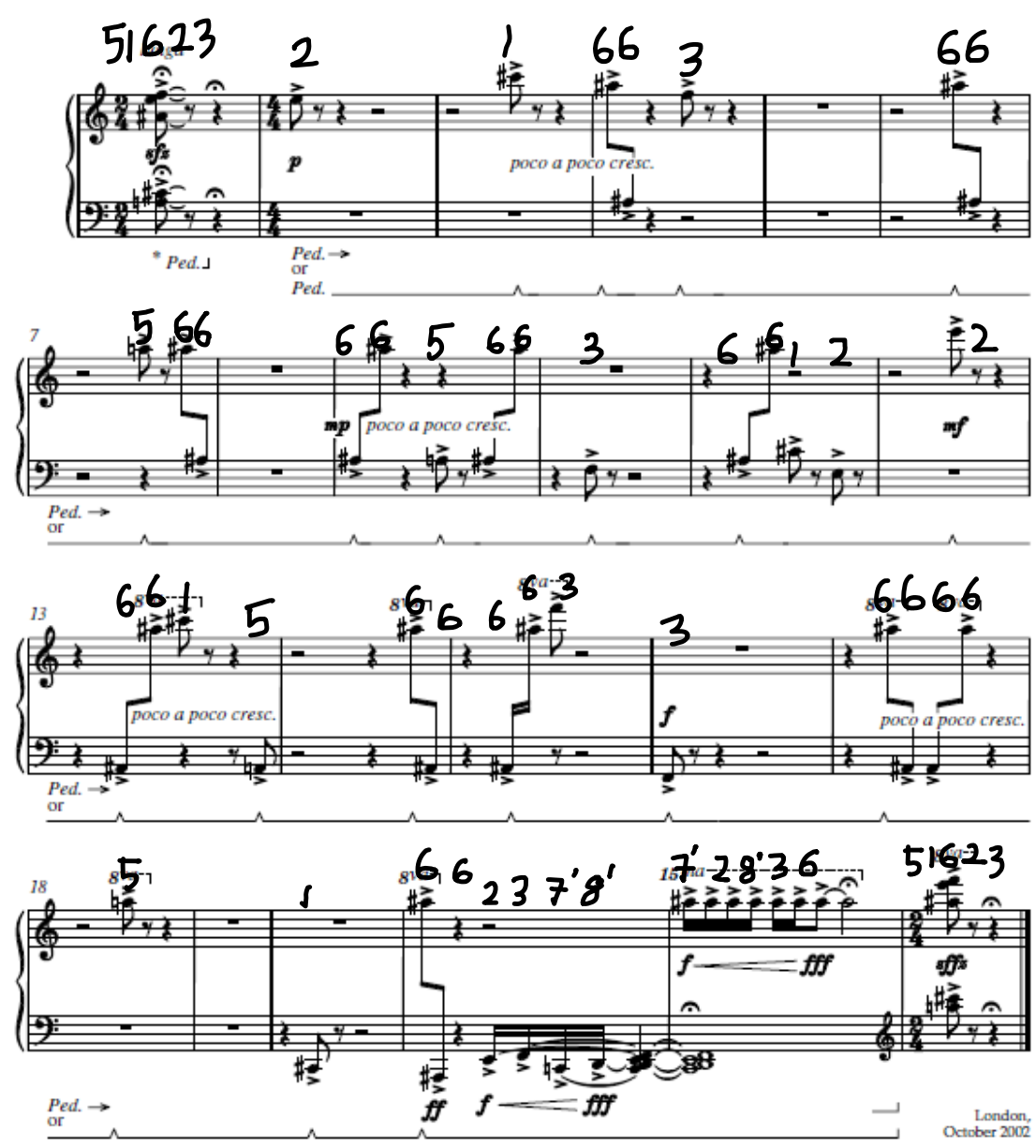

Figure 3: Full score with the numbering system that adapted from the gamelan pelog scale of the Sebuah Pantun for solo piano.

As visible in the first bar and the last bar, the number 5-1-6-2-3 is appearing in the beginning and in the closing which indicates the introduction and the ending as explained in Figures 1 and 2. The seven cycles can be perceived by dividing the numbers into five numbers in one bracket. This means that every five notes can be grouped into one group. For example, the first five notes are in the first bar (51623), which then can be grouped as one. The next five notes (21663) will be grouped as one as well. This method can be applied throughout the piece, except the climax part (bar 21-22). The results of the grouping can be seen as follows: 


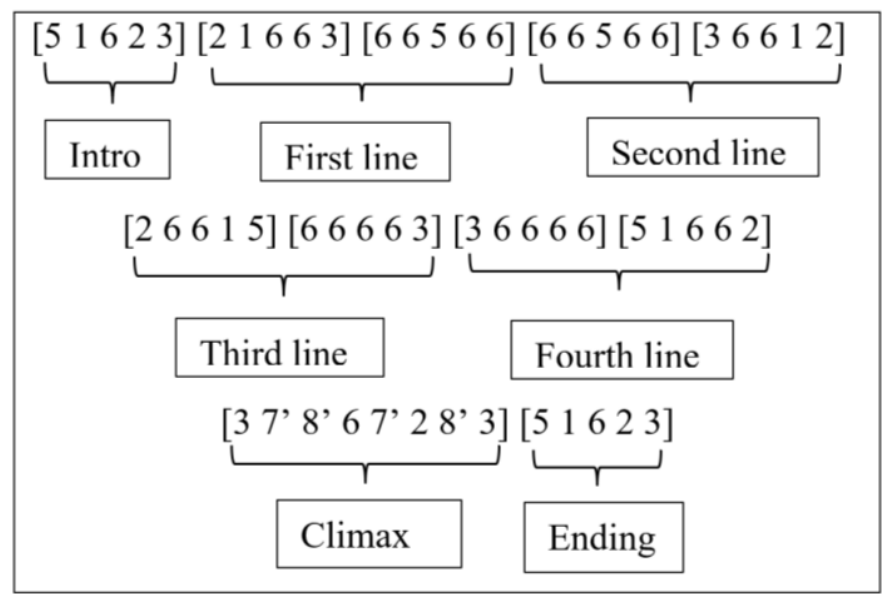

Figure 4: The numbers are grouped into sections based on four-line pantun.

From the result of the grouping in figure 4, it is clear to see the cycles of the number, as if we exclude

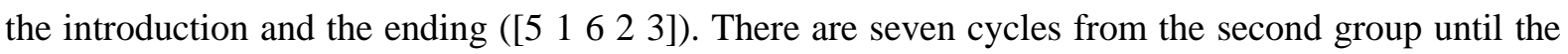

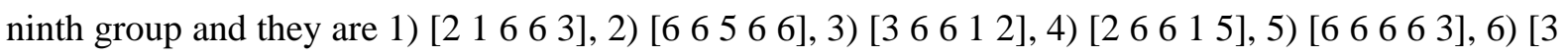
$\left.\begin{array}{llll}6 & 6 & 6 & 6\end{array}\right]$ and 7) [ [ $\left.\begin{array}{llll}5 & 1 & 6 & 6\end{array}\right]$. The other two notes that are added at the end of the piece are numbers 7 and 8 which are $\mathrm{C}$ and $\mathrm{D}$ respectively. These two notes can be seen at the bar $21-22$ in the score or in the tenth group [3 7, $8,67,2$ 8, 3 ] of figure 4 which is the climax of the piece before reaching to the ending. Moreover, another interesting pattern that the composer mentioned in his performance notes is the four small sections that can be seen from bar 2 until bar 21. The first section starts on bar 2 until bar 7. The grouping numbers of this section are [ $\left.\begin{array}{lllll}2 & 1 & 6 & 6 & 3\end{array}\right]$ and $\left[\begin{array}{lllll}6 & 6 & 5 & 6 & 6\end{array}\right]$.

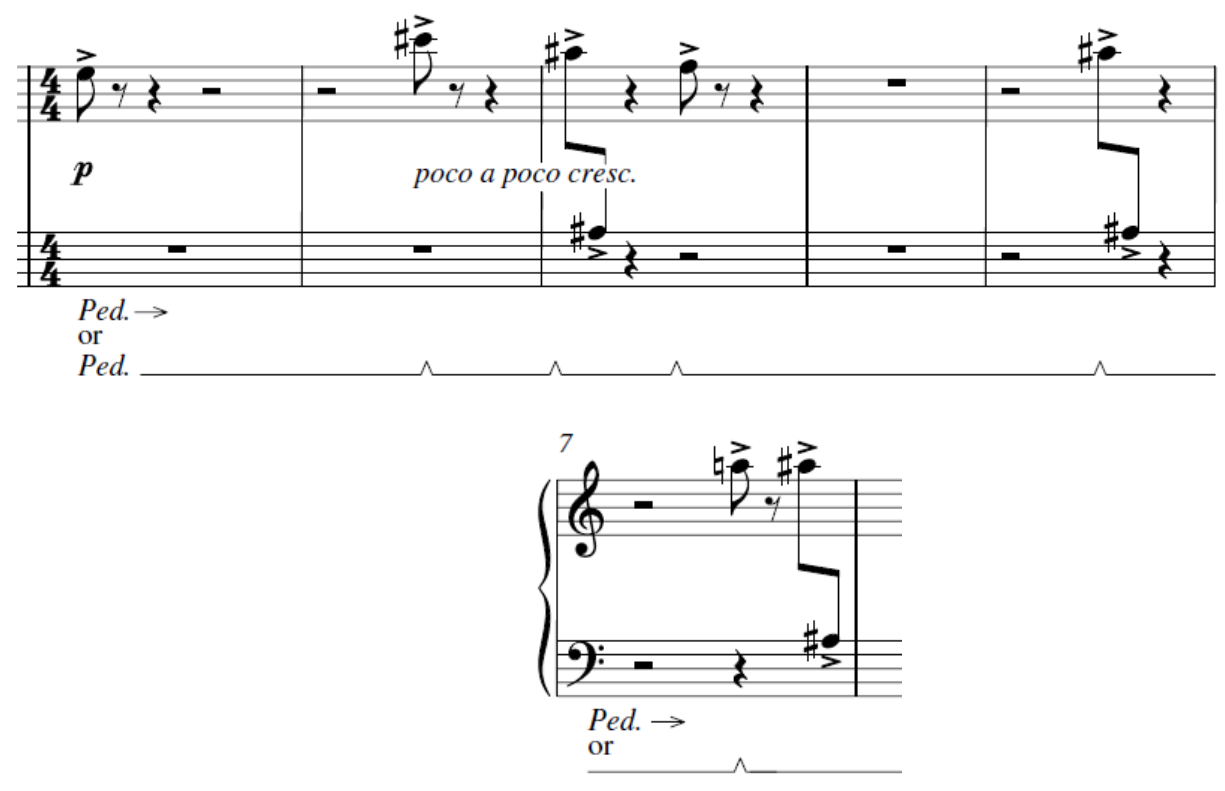

Figure 5: Bar 2-7 of Sebuah Pantun for solo piano.

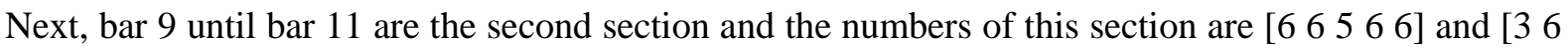
612 ]. The notes and the numbers of the first and the second section are exactly the same, however, in the second section, the notes and numbers are retrograde of the first section but have completely different rhythmic patterns. 


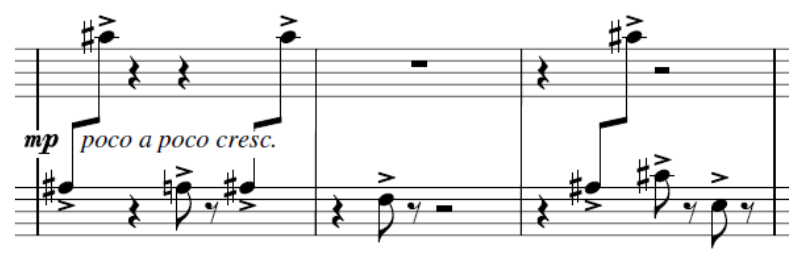

Figure 6: Bar 9-11 of Sebuah Pantun for solo piano.

The third and the fourth sections are using the same method as the first and the second section. The

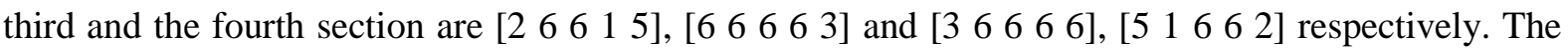
patterns that can be perceived as the fourth section are retrograding the notes of the third but with a different rhythmic pattern.

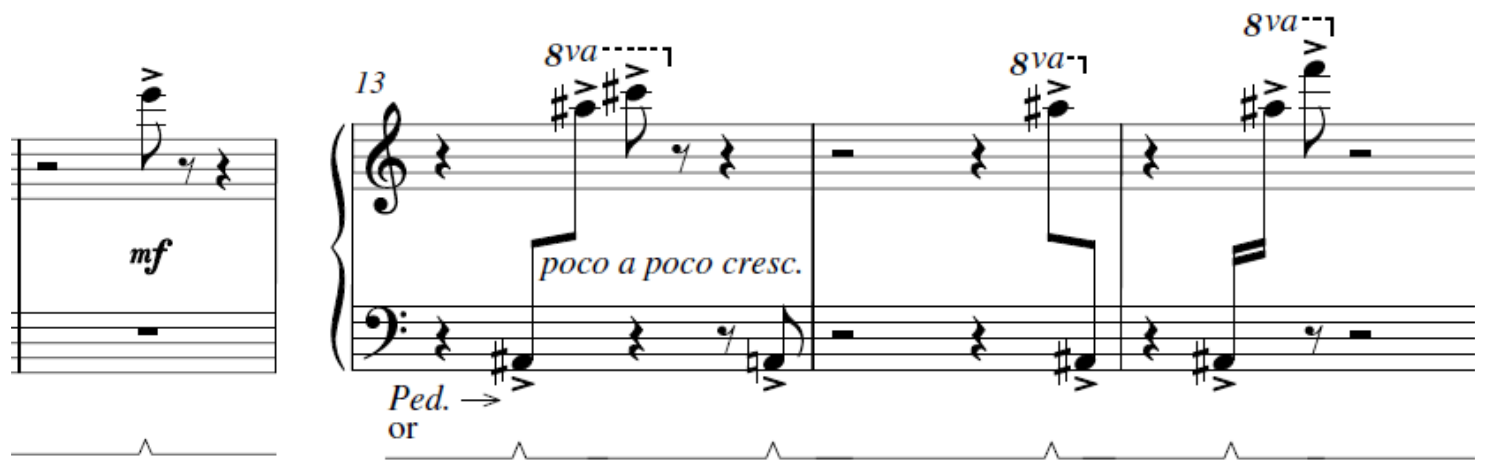

Figure 7: Bar 12-15 of Sebuah Pantun for solo piano.

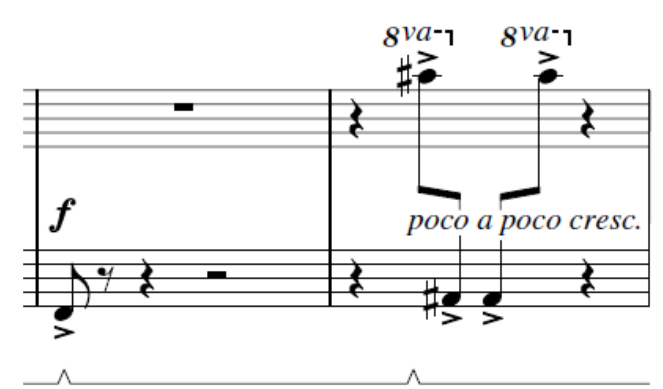

Figure 8: Bar 16-2.

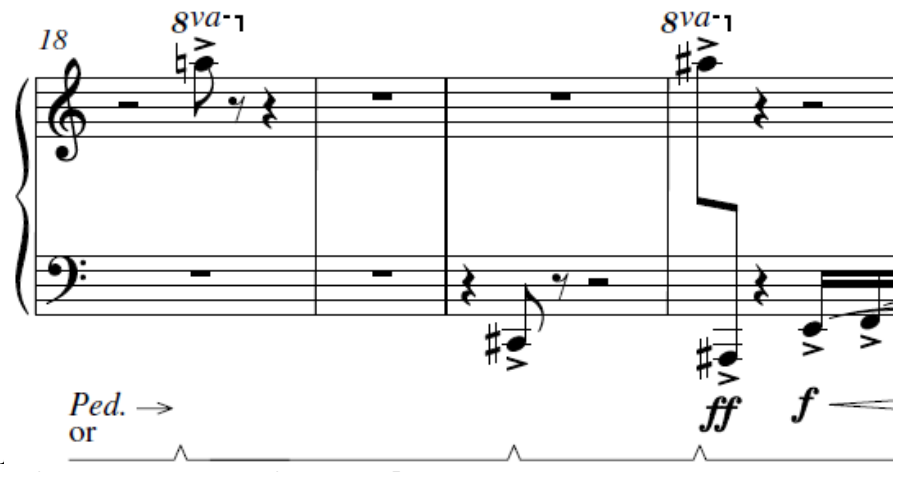

The relation between each section, which in this context are notations and its cycles, and the structure of the pantun is the first and the third line of the 'pantun' related to the first and the third section of the piece. The same thing happens to the second and fourth lines of the pantun which is related to the second and fourth lines of the section. This is also the hidden structure that the composer mentions in the performance notes.

Another way to explain the Sebuah Pantun for solo piano is shown in the table below: 
Table 1: Relation between the pantun and the composition work of Sebuah Pantun for solo piano

\begin{tabular}{lll}
\hline Bar & Description & $\begin{array}{l}\text { Relation with the four-line } \\
\text { pantun }\end{array}$ \\
\hline 1 & $\begin{array}{l}\text { Chord - introduction of the five } \\
\text { series of notes }\end{array}$ & {$[51623]$} \\
\hline $2-7$ & First section & $\begin{array}{l}\text { First line of pantun } \\
{[21663][66566]}\end{array}$ \\
\hline $9-11$ & Second section - Retrograde the & $\begin{array}{l}\text { Second line of pantun } \\
\text { notes of the first section }\end{array}$ \\
\hline $12-15$ & Third section & $\begin{array}{l}\text { Third line of pantun } \\
{[26615][6663]}\end{array}$ \\
\hline $16-21$ & Fourth section - Retrograde the & $\begin{array}{l}\text { Fourth line of pantun } \\
{[36666][51662]}\end{array}$ \\
\hline $21-22$ & notes of the third section & {$\left[37^{\prime} 8^{\prime} 67^{\prime} 28^{\prime} 3\right]$} \\
\hline 23 & Climax & {$[51623]$} \\
\hline
\end{tabular}

\section{Conclusion}

This article elucidates the influence of the local poetry norm on the writing of pieces of music in western-style. The mixture of gamelan and pantun has successfully brought up the sonority of the instruments which explores a wide range and dynamics as in the Sebuah Pantun for solo piano. The imitation of pelog scale and the format of four-line pantun work perfectly with the Western instruments, notation, and style. The deconstruction of Sebuah Pantun for solo piano gives insight and revealed the mind of the composer during the compositional process. Each decision that the composer made has served a purpose that each note sounds as intended and to reach the full potential of the imagination and ideas. This analysis also shows the originality of the composition on how the composer fused between gamelan and pantun with the music notation and western instruments that usually incorporate with local traditional instruments only. This offers a learning opportunity for others that are interested to know how a local Malay tradition of 'pantun' and gamelan traditional instruments can be notated with western instruments and notation, especially in new music.

The results of the music score analysis do not only show the process that the composer has taken but also specifically show which composition techniques have been used throughout the piece. This evidently can be seen when the composer uses serial composition as one of the main elements that hold the composition together. The use of retrograde is highly effective in this work as it subtly influences the melodic and harmonic changes based on the pelog scale.

\section{References}

Audi, R. (1999). The Cambridge Dictionary of Philosophy. Cambridge: Cambridge University Press. Blackburn, S. (1996). The Oxford Dictionary of Philosophy. Oxford: Oxford University Press.

Dillin, A. East to West: Poetry Across the Continents. Retrieved from http://psycochick441.blog.com/ Eoyang, E. (2005). Intercultural Explorations. New York, NY: Amsterdam.

Hose, C. (2017). Step-by-step Music Score Analysis. Retrieved from https://ourpastimes.com/step-bystep-music-score-analysis-12256922.html 
Henry, S. (2008). Focus: Gamelan Music of Indonesia. New York: Routledge.

Meaning of Poetry in English. Retrieved from http://www.oxforddictionaries.com/definition/english/poetry

Nattiez, J.J. (1987). Music and Discourse: Toward Semioloy of Music. United Kingdom: Princeton University Press.

Peck Jin, G. (2012). A Case Study of Cultural Confluence in Malaysian Contemporary Music. Malaysian Music Journal, 3(1), 15-36

Price G.D. (2017). Approaches to Score Study and Interpretation. Retrieved from https://www.smartmusic.com/blog/approaches-to-score-study-and-interpretation/

Raja, M.A., Yusri, H. (2020). Planning a Structure for a Musical Piece: A Composer's Creative Process. International Conference on Arts and Humanities, 7(1), pp. 52-64.

Raleigh, E. The Use and Effect of Pantun in The Hikayat Indraputra. Retrieved from http://mcp.anu.edu.au/papers/rtm/ippantun.html

Siagian, C. B. (2007). Selected Solo Piano Works by Contemporary Malaysian and Indonesian Composers From 1979 - 2007: An Introduction. Oklahoma: ProQuest Learning Company.

The Definition of Poem. Retrieved from http://www.thefreedictionary.com/poem 


\section{Appendix}

for Thalia Myers

Sebuah Pantun

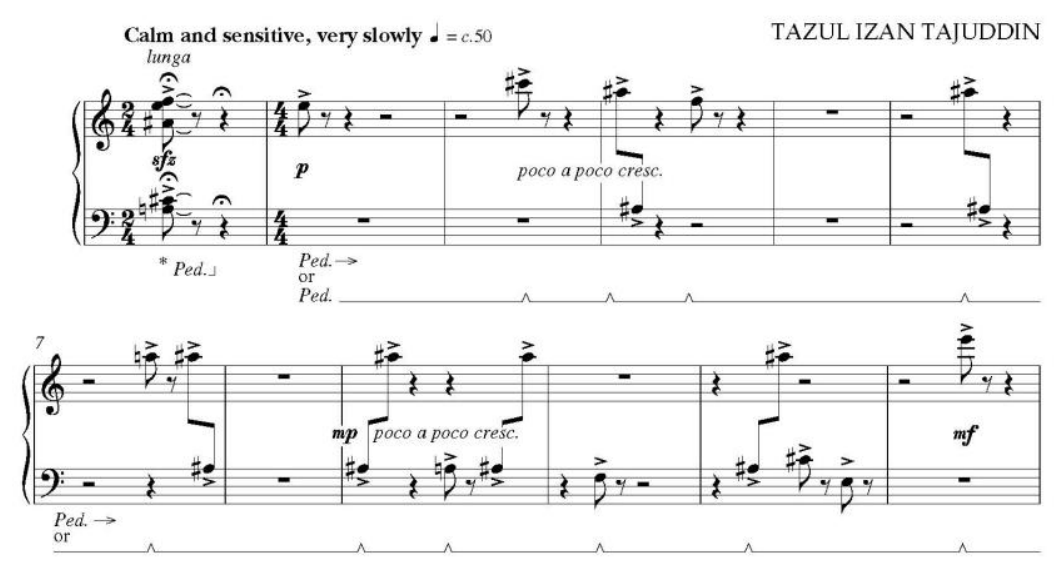

$\oplus$
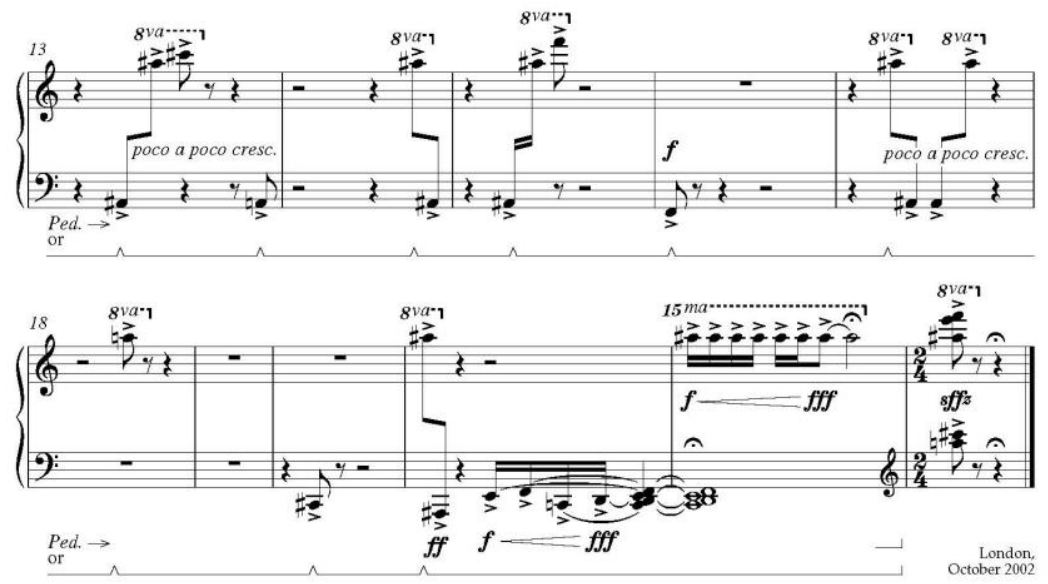

The composer has written: 'A pantun is a traditional Malay verse form, commonly two or four lines long. My piece is derived from five series of nots and seven cyces of numbers. These weave around a hidden structure which is based around four small proportions, intentionally related to the four-lin

pantun
'Strike the notes with conviction but in a calm and meditative state of mind, with a feeling of timelessness. For bars 2-22, two pedalling options are given.'
'Depress the pedal just after the chord is played, to catch the resonance.

(1) 2002 by The Associated Board of the Royal Schools of Music 